\title{
RECURRENCE OF CHAGASIC MEGACOLON AFTER SURGICAL TREATMENT: CLINICAL, RADIOLOGICAL, AND FUNCTIONAL EVALUATION
}

Sergio Eduardo Alonso Araujo, Rodrigo Blanco Dumarco, Sylvio Figueiredo Bocchini, Sergio Carlos Nahas, Desidério Roberto Kiss, Ivan Cecconello

\section{INTRODUCTION}

Chagas disease is an endemic pathology in many regions of Brazil as in most countries of Latin America. The World Health Organization ${ }^{1}$ estimates that there are 17 million infected people in Latin America, including 300,000 new cases per year, and 2 to 3 million patients with chronic complications of the disease. Chagasic megacolon is a late complication of this disease and is defined by an increase in diameter and length of the large bowel. ${ }^{2,3}$

Chagasic megacolon is the result of irreversible destruction of the intramural intestinal nervous system that includes the rectum. ${ }^{4,5} \mathrm{~A}$ progressive and frequently severe constipation associated with complications such as sigmoid volvulus and fecal impaction comprise the clinical picture. ${ }^{6}$

Surgical treatment of chagasic megacolon does not cure the disease; the main objectives are the relief of constipation and abolishment of complication risk. ${ }^{6}$ Operations for chagasic megacolon today comprise a myriad of techniques that involve different extents of colon resection and anastomotic levels, resulting in variable operative morbidity and recurrence. Partial or total resections of the dilated colon have proven to be inadequate in the management of chagasic megacolon due to the preservation of a dyskinetic rectum, which continues to act as a functional obstacle to bowel emptying. High complication rates associated with abdominoperineal pull-through procedures prompted the development of the Habr-Gama technique ${ }^{7}$ at our institution. This operation is an anterior resection of the dilated colon with immediate posterior end-to-side mechanical extraperitoneal colorectal anastomosis. The good results associated with this technique are due to a functional ex-

Department of Gastroenterology, São Paulo University Medical School São Paulo/SP, Brazil.

Discipline of Coloproctology, São Paulo University Medical School - São Paulo/SP, Brazil.

Email: rodrigodumarco@uol.com.br clusion of the diseased rectum through construction of a large (33-mm diameter, circular, stapled) colorectal anastomosis at the posterior rectal wall, avoiding anterior rectal dissection that can offer risk of autonomic nerve damage.

Removal or exclusion of the rectum for patients with chagasic megacolon through an abdominal or abdominoperineal approach is an effective surgical technique. ${ }^{8} \mathrm{Al}$ though postsurgical recurrent constipation may not be observed in some series, ${ }^{9-13}$ it does occur. ${ }^{14}$ To the best of our knowledge, there have been no indexed publications about evaluation and treatment of recurrent cases. Therefore, this communication aims to evaluate clinically and radiologically with radiopaque markers the total colonic transit times for patients who presented with symptomatic recurrence of symptoms after elective surgical treatment of chagasic megacolon outside our institution.

\section{DESCRIPTION OF PATIENTS AND RESULT OF TREATMENT}

We were able to revisit data from 10 patients who previously underwent surgery for chagasic megacolon in other hospitals and had sought medical attention at our institution between January 2001 and January 2003 due to severe recurrence of symptoms.

The mean age was 59.8 years (49 to 70 years); 8 patients $(80 \%)$ were women. We conducted a retrospective evaluation of the relevant clinical data. Studied variables included the time interval between surgical treatment and the relapse of symptoms, the frequency of bowel movements, the need for oral laxatives or enemas, and the occurrence of fecal impaction.

Anastomotic level was evaluated through proctologic examination including rectal endoscopy.

Barium studies were conducted in all patients. Mobilization of the splenic flexure was assumed when a reason- 
able distance between the barium inside the distal transverse colon/left colon and left diaphragmatic dome could be observed associated with a finding of no acute colonic angle at that site. Although subjective, our experience with this rule held largely true when we performed redo operations, mostly for rectal cancer recurrence.

Total colonic transit time with radiopaque markers could be assessed in 7 patients. Five days after ingestion by mouth of one Sitzmarks ${ }^{\circledR}$ (Konsyl Pharmaceuticals, Edison, NJ, USA) capsule, a flat plate abdominal radiograph was obtained. ${ }^{15}$

The mean time interval between elective surgical treatment and symptomatic recurrence was 17.7 years (11-23 years). For those patients with a clinical diagnosis of symptomatic recurrence, the frequency of evacuations was 1.2 (0-2) bowel movements per week. Use of enemas or oral laxatives was reported by $9(90 \%)$ patients. A high colorectal anastomosis was observed through endoscopy in $4(40 \%)$ patients but could not be identified during rectal digital examination in any patient. Fecal impaction leading to urgent medical assistance was observed in $5(50 \%)$ patients.

Radiological evaluation (barium enema) showed dilation of the remnant left colon in $8(80 \%)$ patients, and panmegacolon in $2(20 \%)$. Mobilization of the splenic flexure could be radiologically confirmed in only 2 (20\%) patients.

Total colonic transit time as determined using radiopaque markers could be performed for 7 patients. For all of them, colonic transit time was prolonged. The pattern of outlet obstruction was verified in all patients. Since there was no bowel movement for any patients after a 5-day interval, all 24 markers could be observed accumulated in the left quadrant above the sacral promontory.

\section{DISCUSSION}

Several techniques for surgical treatment of chagasic megacolon have been developed. Best results have been obtained when the rectum is partially or totally bypassed, since as is well known, the rectum can act as an obstacle to intestinal transit. ${ }^{8}$

The Duhamel-Haddad technique is probably the most popular operation among Brazilian surgeons, although few institutions have significant experience with the technique for various reasons. ${ }^{16,17}$ The procedure avoids pelvic and perineal dissection of the rectum, common to other pullthrough procedures such as Swenson's and Soave's operations, by making an anastomosis between the nondilated colon and the posterior wall of the lower rectum. Thus, the Duhamel-Haddad procedure is an option adopted in accordance with the most accepted throry on the pathophysiol- ogy of the disease, namely sigmoid-rectal dyskinesia. ${ }^{3,5,8}$ Recurrence after this operation is quite rare, and complications after it - urinary retention, erectile dysfunction, soiling, and rectal stump fecaloma-occur in a profile that is very similar to, but more rare than that observed after other pull-through procedures (Cutait and Swenson techniques). ${ }^{7,8}$

Although abdominoperineal retrorectal pull-through resection with delayed or immediate anastomosis is an effective alternative, significant morbidity and complications may eventually lead to death or permanent colostomy. This is probably the main reason why many surgeons have decided not to embrace an otherwise popular but technically difficult operation. Necrosis of the pulled-through colon segment and anastomotic site are by far the most common complications, and in our experience, when they occur, permanent colostomy becomes the ultimate solution.

Because of the considerations mentioned above, our institution has adopted (since 1989) as surgical treatment for chagasic megacolonthrough an exclusively abdominal operation performed in 1 stage. For patients who do require surgery, an anterior resection is performed. Reconstruction is accomplished through an end-to-side mechanical extraperitoneal posterior colorectal anastomosis performed 5 to $7 \mathrm{~cm}$ above the anal verge. A laparoscopic access is commonly used at our institution. Since we initiated our experience with this operation, we have observed virtually no recurrences; it must however be pointed out that an incomplete follow-up may have occurred for some patients, because Brazil is a large country and many patients leave São Paulo after improvement of their bowel function, resulting in loss of follow-up. ${ }^{7}$

Recurrence after elective surgical treatment of chagasic megacolon represents a clinically complex situation. To the best of our knowledge, there are no indexed publications that address the issue of recurrence after it; moreover, there are no standard protocols for the evaluation of patients with recurrent constipation after surgical treatment of chagasic megacolon. For instance, patients who present with symptomatic recurrence are no longer young, and clinical comorbidities that may or may not be related to chagasic status (such as cardiac disease, for instance) contribute to an additional risk for a surgical solution. Furthermore, reoperation incurs the need for pelvic dissection; even though this occurs in the clinical scenario of a benign disease, construction of a safe distal colorectal or coloanal anastomosis may not be a simple task.

In order to better understand the clinical picture, we retrospectively evaluated a cohort of patients with chagasic megacolon who underwent elective surgical treatment and presented with symptomatic recurrence.

We could not obtain accurate data regarding the type 
of operation and extent of resected colon segment for these patients, since they did not undergo the first surgical treatment in our institution.

According to our results, the mean time interval until diagnosis of recurrence was 17.7 years (range, 11-23 years). This result indicates that sigmoidectomy may be an effective option only for older patients with chagasic megacolon (which seems to be the case for this cohort of patients), since it is an operation associated with less morbidity than abdominoperineal operations, and recurrence is a late complication.

Although patients could tolerate poor bowel function such as 1 bowel movement per week leading to the need for laxative and enema practice in $90 \%$ of cases, fecal impaction usually demanded medical assistance and was a frequent complication for $50 \%$ of the studied population. In fact, fecal impaction was the most important single reason that drove these patients to nonurgent medical attention.

Information obtained from the proctologic evaluation led to the conclusion that for this cohort of patients, the rectum was neither resected nor bypassed. A high colorectal anastomosis could be identified at proctoscopic evaluation in $4(40 \%)$ patients, and for none of the 10 patients was the anastomosis within reach of an examining finger.

Radiological evaluation confirmed the clinical suspicion of recurrence, since findings of dilated colon with no evidence of anastomotic stenosis were observed in all cases. Dilation of the left colon above the presumed anastomosis was the most common finding, although pan-megacolon was also observed. Observation of an intact splenic left flexure in most $(80 \%)$ of the patients confirmed suspicion of a previous economic left colon resection. Colonoscopic evaluation could be performed for only $2(20 \%)$ patients, since it was judged not routinely necessary for this analysis.

In order to obtain an objective picture regarding the reason for recurrent constipation, we performed a colonic transit time study, even though there is no published experience with this matter. For our patients, total colonic transit time was available for 7 patients and was significantly prolonged, being longer than 5 days. There was no bowel movement for any of these patients, and an accumulation in the left colon of the radiopaque markers was observed. This observation in patients with recurrent chagasic megacolon is similar as that for patients with the condition prior to surgical treatment, indicating that sigmoidectomy represents an option that is undertaken with physiologic understanding of the occurrence of constipation in such patients. After this case study, we still cannot recommend a routine colonic transit time study for patients with recurrent chagasic megacolon, since its results may not alter the surgical strategy for a redo operation of construction of a low colorectal anastomosis.

Clinical, radiological, and functional evidence obtained for 10 patients with recurrent chagasic megacolon after elective surgical treatment indicate that symptomatic recurrence was a late complication after elective surgical treatment and could be radiologically confirmed in all cases. The combination of an intact left flexure with an anastomosis that was not reachable by digital examination was observed in most $(80 \%)$ of patients who entered this study, indicating that sigmoidectomy was the surgical option offered to these patients. Although associated with low morbidity and temporary good results, sigmoidectomy did not modify the results of the colonic transit time study for these patients with chagasic megacolon.

\section{REFERENCES}

1. OMS. Wkly Epidemiol Rec. Chagas disease, Brazil. 2000;75:153-5.

2. Jorge JMN, Habr-Gama A, Yusuf SA, Bocchini SF, Araujo SEA. Physiologic investigation of constipated patients with chagas disease. Colorectal Disease Supplement 2001; 3 (Suppl 1):86.

3. Raia AA. Pathogenesis and treatment of acquired megacolon. Surg Gyn Obstet. 1955;101:69-74.

4. Meneghelli UG. Chagasic enteropathy. Rev Soc Bras Med Trop. 2004;37:252-60.

5. Ribeiro U Jr, Safatle-Ribeiro AV, Gama-Rodrigues JJ, Sohn J, Reynolds JC. Effect of Chagas' disease on nitric oxide-containing neurons in severely affected and unaffected intestine. Dis Colon Rectum. 1998;41:1411-7.

6. Kiss DR: An electron microscope study of the smooth muscle cell in acquired and congenital megacolon. Rev Inst Med Trop São Paulo. 1972;14:178-90.
7. Habr-Gama A, Kiss DR, Bocchini SF, Teixeira MG, Pinotti HW. Chagasic megacolon. Treatment by abdominal recto-sigmoidectomy with mechanical colo-rectal termino-lateral anastomosis. Preliminary results. Rev Hosp Clin Fac Med São Paulo. 1994;49:199-203 (In Portuguese with English abstract).

8. Cutait DE, Cutait R. Surgery of chagasic megacolon. World J Surg. 1991;15:188-97.

9. Moreira H. Tratamento cirúrgico do megacólon chagásico pela técnica de Duhamel-Haddad: experiência pessoal. Arq Gastroenterol. 1971;8:185-90 (In Portuguese with English abastract).

10. Reis Neto JA. Resultados tardios da operação de Duhamel no tratamento do megacólon adquirido. Rev Med Bras. 1972;18:57 (In Portuguese).

11. Habr-Gama A, Bocchini SF, Kiss DR, Sousa Jr AHS. Retossigmoidectomia abdominal com anastomose mecânica colorretal na parede anterior do reto para cirurgia do megacólon. Rev Bras Proct. 1990;10:38 (Suppl. 1) (In Portuguese with English abstract). 
12. Gama RC, Costa JH, Azevedo IF. Tratamento cirúrgico do megacólon chagásico pela técnica de Duhamel-Haddad. Experiência no Hospital Geral de Goiânia. Rev Bras Colo-Proct. 1986;6:84-8 (In Portuguese with English abstract).

13. Pinheiro HB. Abordagem cirúrgica do megacólon chagásico experiência pessoal. Rev Bras Colo-Proct, 1990;35:21-4 (In Portuguese with English abstract).

14. Lins Neto MAF. Duhamel modified surgery with immediate colorectal anastomosis for the treatment of the chagasic megacolon: technique and results. Rev Bras Colo-Proct. 1999;19:263-2.
15. Jorge JMN, Habr-Gama A. Tempo de trânsito colônico total e segmentar: análise crítica dos métodos e estudo em indivíduos normais com marcadores radiopacos. Rev Bras Colo-Proct. 1991;11:55-60 (In Portuguese with English abstract).

16. Kiss DR, Habr-Gama A, Pinotti HW. Chagas'megacolon: considerations on new physiopathological perspectives. Rev Paul Med, 1986;104:14555 (In Portuguese with English abstract).

17. Netinho JG, Cunrath GS, Ronchi LS. Rectosigmoidectomy with ileal loop interposition: a new surgical method for the treatment of chagasic megacolon. Dis Colon Rectum. 2002;45:1387-92. 